УДК $631.445+504.05$

\title{
ТЯЖЕЛЫЕ МЕТАЛЛЫ В ГОРОДСКИХ ПОЧВАХ: ОЦЕНКА СОДЕРЖАНИЯ И ЭКОЛОГИЧЕСКОГО РИСКА
}

\author{
Жарикова Елена Анатольевна, \\ ejarikova@mail.ru
}

Федеральный научный центр Биоразнообразия наземной биоты Восточной Азии Дальневосточного отделения РАН, Россия, 690022, г. Владивосток, пр. 100-летия Владивостока, 159.

\begin{abstract}
Актуальность исследования обусловлена необходимостью выявления особенностей накопления тяжелых металлов в почвах урболандшафотов Владивостока и Уссурийска и установления величины потенциального экологического риска.

Целью работы является оценка геохимического состояния почв различных функциональных зон урболандшафтов с использованием нескольких индексов загрязнения.

Методы. Валовое содержание элементов в почвах определяли методом рентгенфрлуоресцентного анализа на спектрометре EDX-800HS (Shimadzu).

Результаты. Под влиянием сильной техногенной нагрузки в верхних горизонтах почв урболандшафтов в наибольшей степени накапливаются хром, медь, цинк и свинец. Содержание ванадия, кобальта и никеля сравнимо с кларком или ниже его. Средние и максимальные значения комплексных коэфффициентов загрязнения PLI и NPI свидетельствуют о деградации поверхностного слоя городских почв и сильной степени загрязнения тяжелыми металлами. Потенциальный экологический риск колеблется от незначительного до среднего. Степень загрязнения почв различных фуункциональных зон увеличивается в следующем ряду: рекреационная<многоэтажной застройки<транспортно-селитебная<малоэтажной застройки, уровень загрязнения варьирует от оценки «чиста почва» до оценки «сильно загрязненная почва». В некоторых почвах рекреационной зоны выявлена слабая аккумуляция хрома, цинка и меди. В почвах зоны многоэтажной застройки во Владивостоке обнаружено накопление хрома, меди, свинца и цинка (от слабого до среднего), а в Уссурийске отмечено только накопление меди. В почвах транспортно-селитебной зоны и зоны малоэтажной застройки с разной степенью интенсивности аккумулируются хром, медь, свинец и цинк. Более высокие значения как индивидуальных (Igeo, EF, Pl), так и комплексных показателей загрязнения (NPI, PLI, PERI) выявлены в почвах Владивосток.
\end{abstract}

\section{Ключевые слова:}

Почвы урболандшафтов, поллютанты, тяжелые металлы, экологический риск, индекс загрязнения почв.

\section{Введение}

Результатом широкого распространения и взаимосвязи процессов урбанизации и промышленного производства стало снижение качества атмосферного воздуха, поверхностных и подземных вод и почв во всем мире. Активное жилищное и хозяйственное строительство, развитие транспортной сети, проведение новых и ремонт существующих коммуникаций приводят к деградации городских почв и зеленых насаждений. Промышленные выбросы и неуклонно возрастающее количество автотранспорта являются причиной аккумуляции различных токсических веществ в поверхностном слое почв урболандшафтов. Но защитная буферная способность почв небезгранична и может быть утрачена в течение относительно небольшого временного промежутка в результате неправильного использования и нерационального управления. Осознание значимости почвы как базового компонента всех наземных экосистем привело к признанию необходимости сохранения ее потенциала для выполнения ее разнообразных функций, в том числе средообразующей и средоохранной [1-5].

Следствием загрязнения почв может являться ухудшение комфортности среды обитания и здоровья городских жителей, снижение инвестиционной привлекательности жилых и общественно-деловых кварталов. Микрочастицы почв и содержащиеся в них токсиканты способны стать причиной недомогания и различных болезней при проникновении в организм человека, особенно у детей и пожилых людей $[6,7]$.
Поэтому на результаты мониторинга состояния городских почв (особенно параметры химического состава верхних горизонтов) следует обращать внимание при планировании строительства и обустройства лечебных, оздоровительных и детских организаций.

Многолетние данные подтверждают, что на здоровье жителей городов Приморского края непосредственное влияние оказывает низкое качество атмосферного воздуха, способствуя развитию различных заболеваний $[8,9]$. Хотя в последние годы в городах края и наблюдается тренд к снижению загрязнения атмосферного воздуха промышленными предприятиями, доля выбросов автомобильного транспорта неуклонно увеличивается, высокими остаются показатели запыленности воздуха $[10,11]$. В атмосферных взвесях городов юга Дальнего Востока выявлено значительное содержание тонких частиц, в состав которых входят и различные тяжелые металлы [12]. А состав пыли во многом зависит от химического состава городских почв. При этом на изменение элементного состава почв непосредственное влияние оказывают численность населения и особенности городского ландшафта, а именно: размещение промышленного производства, транспортной сети, селитебных и рекреационных зон [13-16].

Для выявления геохимического состояния и характера загрязнения почв в настоящее время в мире широко применяются различные показатели, как простые (индекс геоаккумуляции Igeo, коэффициент концентрации EF, индивидуальный индекс загрязне- 
ния PI), так и комплексные (общий индекс загрязнения PLI, показатель потенциального экологического риска PERI и др.) $[17,18]$. Использование разноплановых характеристик загрязнения почв урболандшафтов и установление экологических рисков их воздействия на сопредельные среды не только способствуют выявлению пространственного распределения загрязнения тяжелыми металлами почв жилых и производственных зон селитебных территорий, но и предоставляют базовую информацию для принятия решений по исправлению ситуации в отношении загрязненных районов.

Целью работы является оценка геохимического состояния почв различных функциональных зон урболандшафтов с использованием нескольких индексов загрязнения.

\section{Объекты и методы}

Исследование элементного состава почв было проведено во Владивостоке, промышленном и портовом городе, и в Уссурийске, промышленном и сельскохозяйственном центре Приморского края. Согласно классификации селитебных территорий [1], это ландшафты населенных пунктов регионального и местного значения. Города были основаны в конце XIX в., поэтому с исторической точки зрения их почвы представляют собой новые молодые компоненты окружающей среды. Названия почв даны в соответствии с «Классификацией и диагностикой почв России» [19], городских почв по Т.В. Прокофьевой с соавторами [13].

Владивосток располагается на пологих склонах сопок южной части полуострова МуравьеваАмурского, почвы развиты на элювиальноделювиальных отложениях коренных пород с низким содержанием мелкозема. Уссурийск лежит в южной части Приханкайской равнины, почвообразующими породами служат четвертичные отложения преимущественно тяжелого состава. Лето теплое, с обилием осадков. Зима малоснежная, умеренно холодная, ветреная. Сумма активных температур 2400-2200, гидротермический коэффициент 1,6-2,0 [20].

В рекреационных зонах с хорошо развитым травяным покровом (парки, пригородные леса) преобладают естественные и поверхностно антропогеннопреобразованные почвы: буроземы типичные и урбистратифицированные. В зоне малоэтажной застройки метеоклиматические условия (увлажнение, скорость и направление ветров и температура) близки к естественным, площадь искусственного покрытия невелика, хорошо развит травянистый покров и древесная растительность. Значительные площади приусадебных участков занимают огороды и сады, поэтому в почвенном покрове доминируют агроземы структурно-метаморфические (Владивосток), агроземы текстурно-дифференцированные (Уссурийск) и урбостратоземы среднемощные на антропогенных отложениях (шлак). Искусственная расчлененность рельефа зоны многоэтажной застройки является причиной особого микроклимата, в частности ветрового и температурного режимов. Эти факторы оказывают прямое воздействие на жизнеспособность и видовой состав травянистого напочвенного покрова. Поскольку значительная часть этой зоны защищена твердым покрытием, большая часть почвенного покрова антропогенно преобразована, и в нем преобладают различной мощности урбостратоземы. Отдельные горизонты в этих почвах отличны по цветовой гамме, гранулометрическому составу, твердости и плотности, количеству привнесенных антропогенных включений. Почвы транспортно-селитебной зоны (преимущественно придорожных газонов и рекультивированных склонов) относятся к глубоко антропогеннопреобразованным, преобладают урбостратоземы маломощные и среднемощные.

Объектами данного исследования являются верхние горизонты городских почв. В рекреационной зоне Владивостока было отобрано 9 образцов, Уссурийска -7 , в зоне малоэтажной застройки - 9 и 7, в зоне многоэтажной застройки - 13 и 11, в транспортноселитебной зоне - 11 и 7 образцов, соответственно. Отбор смешанных почвенных образцов из поверхностного гумусового горизонта (глубина 0-10 см) осуществлялся на площадках мониторинга (размером $5 \times 5$ м) (методом конверта из пяти точек) пластмассовым шпателем. Пробы тщательно диспергировались и перемешивались, масса объединенной пробы составляла не менее 1 кг [21]. Подготовка почвенных проб и определение элементного анализа выполнены по аттестованной методике [22].

Элементный состав образцов (в трехкратной повторности) проводили методом энергодисперсионной рентгенфлуоресцентной спектроскопии (energy dispersive X-ray fluorescence spectroscopy) на анализаторе EDX 800HS-P (Shimadzu, Япония), оснащенном родиевым катодом в формате количественного анализа в вакуумной среде. Использовались государственные стандартные образцы сравнения (ГСО 901-76, ГСО 902-76, ГСО 903-76, ГСО 2498-83, ГСО 2499-83, ГСО 2507-83). Через каждые пять проб проводился анализ стандартного образца (ГСО 2507-83). Параметры измерения: напряжение - 50 кВ, сила тока - 100 мА, время определения - 300 с, «мертвое» время - $20 \%$, размер коллиматора - 10 мм. Метод обладает высокой точностью, нижний предел обнаружения метода не более 3-4 мг/кг [23]. В почвенных пробах определяли валовое содержание тяжелых металлов разных классов опасности $\mathrm{V}, \mathrm{Cr}, \mathrm{Co}, \mathrm{Ni}, \mathrm{Cu}, \mathrm{Zn}, \mathrm{Pb}$ и Ti как эталонного элемента

Bce образцы почв имеют легкосуглинистый гранулометрический состав с преобладанием фракции крупной пыли, слабокислую и нейтральную реакцию среды и содержат различные по количеству и качеству следы жизнедеятельности населения, в том числе мусор (как строительный, так и коммунальный), печную золу и т. д. [24-26]. Все химикоаналитические работы выполнены автором в аналитическом центре ФНЦ Биоразнообразия ДВО РАН.

Индекс геоаккумуляции (Geoaccumulation Index) служит геохимическим критерием для выявления загрязнения

$\operatorname{Igeo}=\log 2(\mathrm{Ci} / 1,5 \mathrm{~GB})$, 
где $\mathrm{Ci}$ - содержание металла в верхнем горизонте; GB - фоновое содержание (или кларк в почве), в настоящей работе использованы данные [23]. Он ранжирует семь классов состояния почв: Igeo $<0$ - чистые; $0<$ Igeo $<1$ - загрязнение от слабого до среднего; $1<$ Igeo $<2$ - средняя степень загрязнения; $2<$ Igeo $<3$ загрязнение от среднего до сильного; $3<$ Igeo $<4$ сильное загрязнение; $4<\operatorname{Igeo<5~-~загрязнение~от~силь-~}$ ного до очень сильного; 5<Igeо - очень сильное загрязнение. Коэффициент 1,5 применяется для выявления даже незначительного антропогенного воздействия [27].

Коэффициент концентрации EF (Enrichment Factor) вычисляется для определения накопления и происхождения металла в почве (природное или антропогенное), при этом учитывается содержание какоголибо стабильного эталонного элемента, в нашем случае титана $\left(\mathrm{C}_{\mathrm{Ti}}\right)$,

$$
\mathrm{EF}=\left(\mathrm{Ci} / \mathrm{C}_{\mathrm{Ti}}\right) /\left(\mathrm{GBi} / \mathrm{GB}_{\mathrm{Ti}}\right) .
$$

Он позволяет выявить пять уровней накопления металла: минимальное $(\mathrm{EF}<2)$, среднее $(2-5)$, значительное (5-20), очень высокое (20-40), чрезвычайно высокое $(>40)[17,18]$.

Индекс загрязнения (Single Pollution Index),

$$
\mathrm{PI}=\mathrm{Ci} / \mathrm{GB} \text {. }
$$

Используется для выявления наличия загрязнения отдельными поллютантами. Значение $\mathrm{PI}<1$ свидетельствует об отсутствии загрязнения, $1<\mathrm{PI}<2-0$ слабом загрязнения, $2<\mathrm{PI}<3-$ о среднем, $3<\mathrm{PI}<5-0$ сильном, РІ $>5$ - об очень сильном загрязнении. Индекс является основой для расчета комплексных показателей загрязнения $[17,18]$.

PLI - коэффициент загрязнения (Pollution Load Index), рассчитывается как геометрическое среднее от PI

$$
\mathrm{PLI}=\left(\mathrm{PI}_{1} * \mathrm{PI}_{2} * \ldots \mathrm{PI}_{\mathrm{n}}\right)^{1 / \mathrm{n}} .
$$

Коэффициент указывает на совокупную аккумуляцию тяжелых металлов. Значение PLI ниже 1,0 свидетельствует об отсутствии загрязнения [28, 29].
Показатель потенциального экологического риска (Potential Ecological Risk)

$$
\mathrm{PERI}=\sum \mathrm{PI}_{1} * \mathrm{~T}_{\mathrm{i}},
$$

где $\mathrm{T}_{\mathrm{i}}$ - коэффициент токсичности тяжелого металла. Значения $\mathrm{T}_{\mathrm{i}}$ для $\mathrm{Zn}, \mathrm{V}, \mathrm{Cr}, \mathrm{Co}, \mathrm{Pb}, \mathrm{Ni}, \mathrm{Cu}$ равны 1, 2, 2, 5 , 5,5 соответственно [30, 31]. Значение PERI $<90$ означает низкий уровень экологической опасности, 90-180 средний, 180-360 - высокий, 360-720 - очень высокий, $>720$ - чрезвычайно высокий $[17,32,33]$.

Индекс загрязнения Nemerow (NPI) (Nemerow Pollution Index) очень широко используется для оценки качества почв, поскольку учитывает вклад не только каждого загрязнителя, но и потенциальную опасность металла-загрязнителя с наибольшим содержанием.

$$
\mathrm{NPI}=\sqrt{ } 0,5\left(\mathrm{PI}_{1 \text { max }}{ }^{2}+\mathrm{PI}_{1 \text { ave }}{ }^{2}\right) \text {, }
$$

где $\mathrm{PI}_{1 \max }$ - максимальное значение PI среди n металлов, а $\mathrm{PI}_{\text {lave }}$ - среднее значение PI. NPI ранжирует пять классов загрязнения почв: NPI $<0,7$ - чистая почва, $0,7 \leq \mathrm{NPI}<1,0$ - пограничный уровень, $1,0 \leq \mathrm{NPI}<2,0-$ слабое загрязнение, 2,0 $\leq \mathrm{NPI}<3,0$ - среднее , NPI $>3$ сильное загрязнение $[17,18]$.

\section{Результаты исследования и обсуждение}

В почвах Владивостока среднее содержание цинка и свинца значительно выше, чем в почвах Уссурийска, содержание ванадия, хрома, кобальта, никеля и меди отличается незначительно (табл. 1). По сравнению с кларком почвы селитебных районов почвы Владивостока обогащены хромом, медью, цинком, свинцом, а почвы Уссурийска - медью. Содержание кобальта и никеля сравнимо с кларком, а содержание ванадия ниже его [27]. Величины коэффициента вариации характеризуют как однородную степень рассеяния для ванадия, хрома и кобальта, не дифференцированную для никеля и меди, сильно неоднородную для цинка (во Владивостоке) и крайне неоднородную для цинка (в Уссурийске) и свинца в обоих городах [33]. Подобное неоднородное распределение в отношении свинца и

\begin{tabular}{|c|c|c|c|c|c|c|c|}
\hline Показатели/Statistics & $\mathrm{V}$ & $\mathrm{Cr}$ & Co & $\mathrm{Ni}$ & $\mathrm{Cu}$ & $\mathrm{Zn}$ & $\mathrm{Pl}$ \\
\hline \multicolumn{8}{|c|}{ Владивосток/Vladivostok } \\
\hline Минимум/Minimum & 50 & 80 & 10 & 10 & 10 & 60 & 10 \\
\hline Максимум/Maximum & 150 & 130 & 20 & 90 & 250 & 1070 & 470 \\
\hline Среднее/Mean & 94 & 92 & 16 & 29 & 81 & 259 & 89 \\
\hline Медиана/Median & 90 & 92 & 20 & 20 & 70 & 186 & 50 \\
\hline Стандартная ошибка/Standard error & 3,73 & 3,73 & 0,77 & 2,54 & 6,58 & 31,99 & 14,61 \\
\hline Коэффициент вариации/Coefficient of variation, \% & 26 & 11 & 33 & 56 & 53 & 80 & 106 \\
\hline \multicolumn{8}{|c|}{ Уссурийск/Ussuriysk } \\
\hline Минимум/Minimum & 50 & 70 & 10 & 10 & 40 & 11 & 10 \\
\hline Максимум/Maximum & 130 & 260 & 40 & 100 & 240 & 890 & 410 \\
\hline Среднеe/Mean & 89 & 94 & 15 & 29 & 81 & 156 & 61 \\
\hline Медиана/Median & 90 & 90 & 10 & 25 & 70 & 100 & 35 \\
\hline Стандартная ошибка/Standard error & 3,58 & 5,24 & 1,21 & 2,81 & 8,26 & 27,21 & 15,11 \\
\hline Коэффициент вариации/Coefficient of variation, \% & 23 & 31 & 47 & 56 & 55 & 102 & 143 \\
\hline Харбин/Harbin [35] & - & 32,86 & - & 39,82 & 24,29 & 58,22 & 24,29 \\
\hline Чанчунь/Changchun [35] & - & 94,53 & - & - & 68,41 & 416,71 & 93,26 \\
\hline Фоновое содержание (кларк)/Geochemical background (clarke) [27] & 129 & 59,5 & 11,3 & 29 & 38,9 & 70 & 27 \\
\hline Кларк в городских почвах/Clarks in urban soils [1] & 104,9 & 80 & 14,1 & 33 & 39 & 158 & 54,5 \\
\hline
\end{tabular}
цинка в верхнем слое городских почв может быть результатом значительного техногенного прессинга [34].

Таблица 1. Тяжелье металль в городских почвах Владивостока и Уссурийска (мг/кг)

Table 1. Heavy metal concentrations in urban soils of Vladivostok and Ussuriysk ( $\mathrm{mg} / \mathrm{kg})$ 
При сравнении содержания исследуемых опасных элементов в почвах городов близлежащей пограничной провинции Хейлудзян (Китай) установлено, что в почвах Харбина содержание тяжелых металлов намного ниже (кроме никеля), а почвы Чанчуня сильнее загрязнены цинком и свинцом и меньше медью [35], чем почвы городов южной части Приморья.

Анализ значений индексов геоаккумуляции Igeo показал, что большинство почв Владивостока и Уссурийска в отношении ванадия, кобальта, никеля характеризуются как чистые, в отношении хрома, меди, цинка и свинца - умеренно загрязненные, хотя максимальные значения для последних трех элементов указывают на высокий уровень загрязнения (табл. 2). Средние значения коэффициента концентрации ЕF в городских почвах позволяют установить, что накопление ванадия, никеля, кобальта, хрома, меди (во
Владивостоке) минимально, а накопление свинца, цинка, меди (в Уссурийске) среднее. Максимальные значения EF свидетельствуют о значительном обогащении отдельных образцов почв свинцом, цинком и медью. Средние показатели индекса загрязнения PI характеризуют почвы как чистые в отношении ванадия и никеля (во Владивостоке), слабо загрязненные в отношении хрома, кобальта и никеля (в Уссурийске), загрязненные в средней степени в отношении меди, цинка и свинца (в Уссурийске) и сильнозагрязненные в отношении цинка и свинца (во Владивостоке). Эти данные вполне согласуются с содержанием металлов в составе атмосферного воздуха городов [12]. Максимальные показатели указывают на среднюю степень загрязнения в отношении хрома, кобальта и никеля и очень высокую степень в отношении меди, цинка и свинца в отдельных образцах почв обоих городов.

Таблица 2. Статистические показатели отдельных индексов в поверхностных слоях городских почв

Table 2. $\quad$ Statistics of single indexes in the urban soils

\begin{tabular}{|c|c|c|c|c|c|c|c|}
\hline Показатели/Statistics & $\mathrm{V}$ & $\mathrm{Cr}$ & $\mathrm{Co}$ & $\mathrm{Ni}$ & $\mathrm{Cu}$ & $\mathrm{Zn}$ & $\mathrm{Pb}$ \\
\hline \multicolumn{8}{|c|}{ Igeo } \\
\hline \multicolumn{8}{|c|}{ Владивосток/Vladivostok } \\
\hline Минимум/Minimum & $-1,95$ & $-0,16$ & $-0,76$ & $-2,12$ & $-2,54$ & $-0,81$ & $-2,02$ \\
\hline Максимум/Maximum & $-0,37$ & 0,54 & 0,24 & 1,05 & 2,09 & 3,35 & 3,54 \\
\hline Среднее/Mean & $-1,09$ & 0,04 & $-0,19$ & $-0,81$ & 0,31 & 0,93 & 0,53 \\
\hline \multicolumn{8}{|c|}{ Уссурийск/Ussuriysk } \\
\hline Минимум/Minimum & $-1,09$ & $-0,35$ & $-0,76$ & $-2,12$ & $-0,54$ & $-3,25$ & $-2,12$ \\
\hline Максимум/Maximum & $-0,57$ & 1,54 & 1,24 & 1,21 & 2,04 & 3,08 & 3,34 \\
\hline Среднее/Mean & $-1,17$ & 0,04 & $-0,31$ & $-0,75$ & 0,39 & 0,12 & $-0,15$ \\
\hline \multicolumn{8}{|c|}{ EF } \\
\hline \multicolumn{8}{|c|}{ Владивосток/Vladivostok } \\
\hline Минимум/Minimum & 0,47 & 0,89 & 0,61 & 0,21 & 0,22 & 0,82 & 0,37 \\
\hline Максимум/Maximum & 0,78 & 2,31 & 2,22 & 2,76 & 8,01 & 13,36 & 17,41 \\
\hline Среднее/Mean & 0,64 & 1,43 & 1,26 & 0,91 & 1,96 & 3,31 & 3,31 \\
\hline \multicolumn{8}{|c|}{ Уссурийск/Ussuriysk } \\
\hline Минимум/Minimum & 0,52 & 0,94 & 0,66 & 0,26 & 0,76 & 0,19 & 0,28 \\
\hline Максимум/Maximum & 0,71 & 2,75 & 2,35 & 3,35 & 7,73 & 7,99 & 13,63 \\
\hline Среднее/Mean & 0,62 & 1,46 & 1,19 & 0,95 & 2,12 & 2,01 & 2,14 \\
\hline \multicolumn{8}{|c|}{ PI } \\
\hline \multicolumn{8}{|c|}{ Владивосток/Vladivostok } \\
\hline Минимум/Minimum & 0,39 & 1,34 & 0,88 & 0,34 & 0,26 & 0,86 & 0,38 \\
\hline Максимум/Maximum & 1,16 & 2,18 & 1,77 & 3,11 & 6,43 & 15,29 & 17,41 \\
\hline Среднеe/Mean & 0,73 & 1,54 & 1,39 & 0,99 & 2,07 & 3,69 & 3,31 \\
\hline \multicolumn{8}{|c|}{ Уссурийск/Ussuriysk } \\
\hline Минимум/Minimum & 0,39 & 1,18 & 0,88 & 0,34 & 1,03 & 0,16 & 0,37 \\
\hline Максимум/Maximum & 1,01 & 4,37 & 3,54 & 3,45 & 6,17 & 12,71 & 15,19 \\
\hline Среднеe/Mean & 0,69 & 1,59 & 1,33 & 1,01 & 2,23 & 2,22 & 2,28 \\
\hline
\end{tabular}

Значения комплексных коэффициентов загрязнения PLI и NPI, как средние, так и максимальные, свидетельствуют о деградации поверхностного слоя городских почв и сильной степени загрязнения тяжелыми металлами. При этом средние значения потенциального экологического риска PERI характеризуют его как незначительный, а максимальные как средний (табл. 3). Анализ значений коэффициентов геоаккумуляции Igeo позволил установить основные закономерности содержания различных тяжелых металлов в верхнем горизонте почв различных городских зон (рис. 1). В почвах рекреационных зон Владивостока выявлено загрязнение от слабого до среднего уровня в отношении хрома и цинка, в Уссурийске подобное загрязнение установлено в отношении меди, для остальных тяжелых металлов значения Igeo отрица- тельные, что указывает на чистоту почв. Наименьшие значения коэффициентов геоаккумуляции обнаружены в обоих городах для ванадия и никеля.

В зоне малоэтажной застройки отмечено накопление хрома и меди, для обоих металлов загрязнение варьирует от слабого до среднего, свинца (загрязнение от слабого до среднего в Уссурийске) и цинка (средняя степень загрязнения в Уссурийске и загрязнение от среднего до сильного во Владивостоке). В отношении ванадия, кобальта, никеля почвы данной зоны характеризуются как чистые.

Почвы зоны многоэтажной застройки во Владивостоке обогащены хромом, медью, свинцом и цинком (загрязнение от слабого до среднего). В Уссурийске подобный уровень загрязнения установлен только в отношении меди, остальные элементы имеют нулевое 
(хром) и отрицательное значение Igeo, наименьшие показатели присущи ванадию, никелю и свинцу. В почвах транспортно-селитебной зоны Владивостока отмечено накопление хрома, меди, цинка и свинца, т. е. выявлено загрязнение от слабого до среднего.
В Уссурийске подобное загрязнение установлено для хрома, меди и свинца. В почвах всех зон Владивостока выявлена аккумуляция цинка, а в почвах Уссурийска - меди. Значения Igeо в отношении свинца во Владивостоке повсеместно выше, чем в Уссурийске.

Таблица 3. Статистические показатели комплексных показателей загрязнения в городских почвах

Table 3. $\quad$ Statistics of total complex indexes in the urban soils

\begin{tabular}{|c|c|c|c|c|c|c|}
\hline \multirow[b]{2}{*}{$\begin{array}{c}\text { Показатели } \\
\text { Statistics }\end{array}$} & \multicolumn{2}{|r|}{ NPI } & \multicolumn{2}{|r|}{ PLI } & \multicolumn{2}{|r|}{ PERI } \\
\hline & $\begin{array}{l}\text { Уровень } \\
\text { Value }\end{array}$ & $\begin{array}{c}\text { Оценка загрязнения } \\
\text { Pollution status }\end{array}$ & $\begin{array}{l}\text { Уровень } \\
\text { Value }\end{array}$ & $\begin{array}{c}\text { Оценка загрязнения } \\
\text { Pollution status }\end{array}$ & $\begin{array}{l}\text { Уровень } \\
\text { Value }\end{array}$ & $\begin{array}{c}\text { Экологический риск } \\
\text { Ecological risk }\end{array}$ \\
\hline \multicolumn{7}{|c|}{ Владивосток/Vladivostok } \\
\hline $\begin{array}{l}\text { Минимум } \\
\text { Minimum }\end{array}$ & 1,2 & Слабое/Slight & 0,7 & $\begin{array}{c}\text { Отсутствует } \\
\text { No metal } \\
\text { contamination } \\
\end{array}$ & 18 & $\begin{array}{c}\text { Незначительный } \\
\text { Low }\end{array}$ \\
\hline $\begin{array}{l}\text { Максимум } \\
\text { Maximum }\end{array}$ & 12,7 & Сильное/Heavy & 2,8 & $\begin{array}{c}\text { Деградация } \\
\text { Deterioration of soil } \\
\text { quality }\end{array}$ & 123 & $\begin{array}{l}\text { Средний } \\
\text { Moderate }\end{array}$ \\
\hline $\begin{array}{l}\text { Среднее } \\
\text { Mean }\end{array}$ & 3,4 & Сильное/Heavy & 1,4 & $\begin{array}{c}\text { Деградация } \\
\text { Deterioration of soil } \\
\text { quality }\end{array}$ & 50 & $\begin{array}{c}\text { Незначительный } \\
\text { Low }\end{array}$ \\
\hline \multicolumn{7}{|c|}{ Уссурийск/Ussuriysk } \\
\hline $\begin{array}{l}\text { Минимум } \\
\text { Minimum }\end{array}$ & 1,1 & Слабое/Slight & 0,7 & $\begin{array}{c}\text { Отсутствует } \\
\text { No metal } \\
\text { contamination }\end{array}$ & 19 & $\begin{array}{c}\text { Незначительный } \\
\text { Low }\end{array}$ \\
\hline $\begin{array}{l}\text { Максимум } \\
\text { Maximum }\end{array}$ & 11 & Сильное/Heavy & 3,1 & $\begin{array}{c}\text { Деградация } \\
\text { Deterioration of soil } \\
\text { quality }\end{array}$ & 102 & $\begin{array}{l}\text { Средний } \\
\text { Moderate }\end{array}$ \\
\hline $\begin{array}{l}\text { Среднее } \\
\text { Mean }\end{array}$ & 2,9 & Сильное/Heavy & 1,3 & $\begin{array}{c}\text { Деградация } \\
\text { Deterioration of soil } \\
\text { quality }\end{array}$ & 41 & $\begin{array}{c}\text { Незначительный } \\
\text { Low }\end{array}$ \\
\hline
\end{tabular}

1

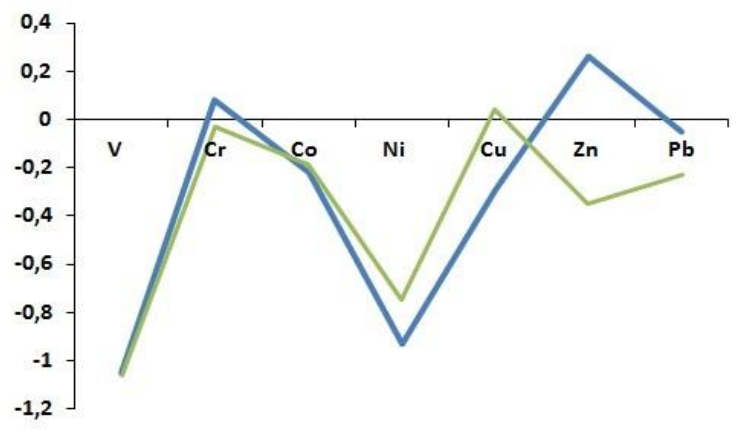

3

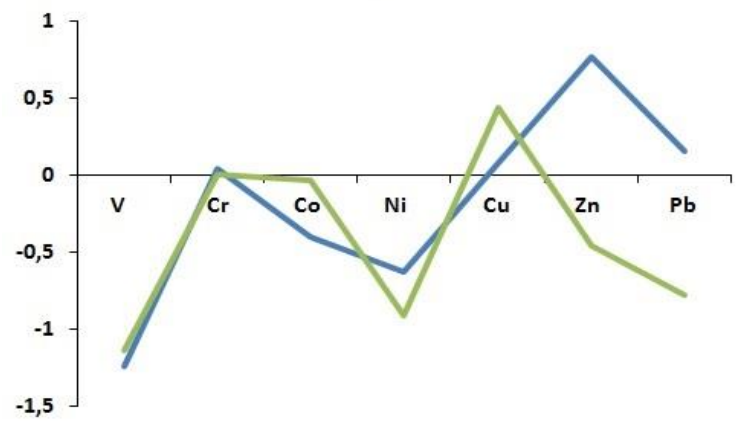

2

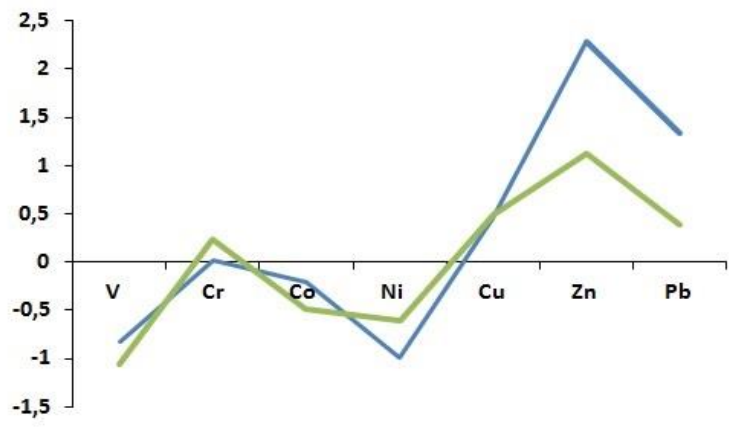

4

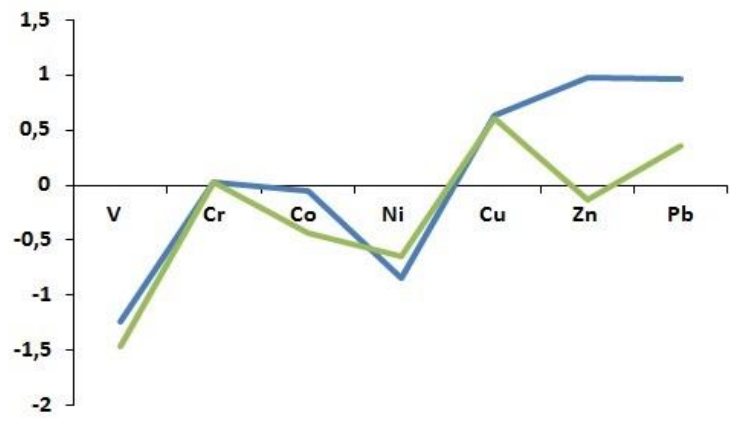

- Владивосток - Уссурийск

Рис. 1. Значения коэффициентов геоаккумуляции Igео в почвах различных функциональных зон городов: 1 - рекреаиионная, 2 - малоэтажной застройки, 3 -многоэтажной застройки, 4 - транспортно-селитебная

Fig. 1. Igeo in urban soils of different functional zones: 1 - recreational, 2 - low-rise buildings, 3 - residential multistory, 4 - transport and residential 
Судя по значениям комплексного индекса загрязнения (Nemerow NPI) степень загрязнения почв в обоих городах возрастает в следующем порядке: рекреационная зона $(1,5-1,8$, слабое загрязнение $)<$ зона многоэтажной застройки $(1,8-2,0$, слабое загрязнение во Владивостоке и среднее в Уссурийске) < транспортно-селитебная зона $(2,1-3,9$, среднее загрязнение в Уссурийске и сильное во Владивостоке) < зона малоэтажной застройки (2,9-6,2, среднее загрязнение в Уссурийске и сильное во Владивостоке) (рис. 2). Анализ значений коэффициента загрязнения PLI несколько иначе характеризует ситуацию, хотя порядок нарастания загрязнения в различных зонах остается прежним. Подтвержден факт загрязнения почв во всех зонах городов, но самые высокие значения PLI получены для почв малоэтажной застройки Уссурийска. Средние значения потенциального экологического риска PERI позволяют оценить его как незначительный во всех зонах обоих городов, а максимальные - как средний в зонах транспортноселитебной и малоэтажной застройки Владивостока (123 и 107) и в зоне малоэтажной застройки Уссурийска (102).
Более высокий уровень загрязнения почв зоны малоэтажной застройки может быть вызван сочетанием нескольких факторов. Большинство домохозяйств в зоне малоэтажной застройки имеют печное отопление, угольная пыль и шлак, так же как и продукты сжигания бытового мусора, накапливаются в почвах приусадебных участков. Последние могут содержать до 6500 мг/кг цинка, до 4000 мг/кг меди, до 1600 мг/кг свинца, до 640 мг/кг хрома. Угольная зола в среднем содержит 120 мг/кг ванадия, 45 мг/кг меди, 18 мг/кг кобальта, 36 мг/кг никеля, 65 мг/кг меди, 142 мг/кг цинка [36], в золе ТЭЦ-2 Владивостока обнаружено 30-50 мг/кг цинка, 7-50 мг/кг меди, 5-600 мг/кг кобальта, 3-80 мг/кг никеля [37]. В составе угольной пыли может находиться 30-100 мг/кг ванадия, 10-100 мг/кг хрома, 30-100 мг/кг кобальта и меди, 40-200 мг/кг никеля, 50-290 мг/кг цинка и 45-300 мг/кг свинца [38]. Следует обратить внимание и на тот факт, что повсеместно в зимний период городские коммунальные службы для отсыпки дорог и тротуаров в зоне многоэтажной застройки и транспортно-селитебной зоне используют шлак, который весной с талыми водами попадает на газоны и придомовые участки, загрязняя почвы и увеличивая количество пыли в воздухе.
A

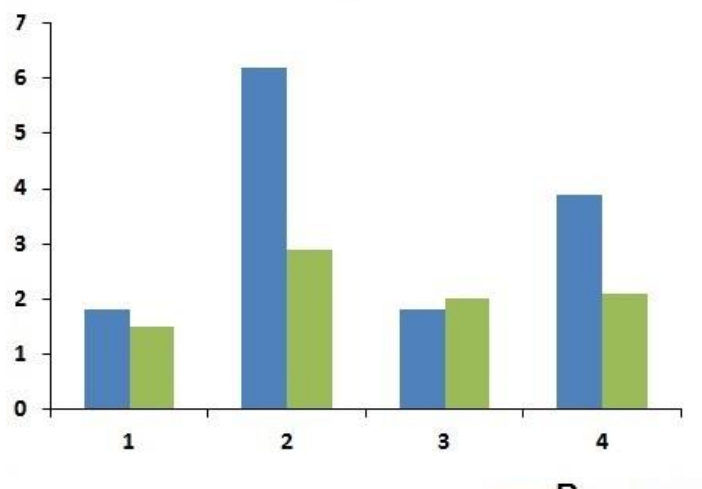

B

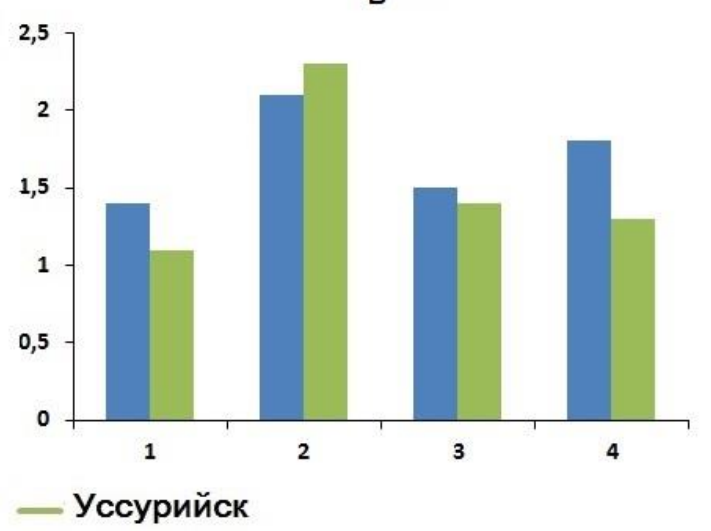

Puc. 2. Средние значения индекса загрязнения Nemerow NPI (A) и коэффициента загрязнения PLI (B) в почвах различных функииональных зон. Условные обозначения см. на рис. 1

Fig. 2. Average Nemerow Pollution Index (A) and Pollution Load Index (B) in urban soils of different functional zones. For symbols see Fig. 1

На приусадебных садах и огородах жители активно и бесконтрольно используют широкий ассортимент продукции сельскохозяйственной химии, в которой в виде примесей содержатся тяжелые металлы. Так, в фосфорных удобрениях содержание хрома находится в пределах 10,4-72,7 мг/кг, меди - 2,8-82,6 мг/кг, цинка - 8,8-180,6 мг/кг, никеля - 7,0-26,9 мг/кг, свинца 5,1-30,7 мг/кг, ванадия - до 38 мг/кг [39]. Азотные удобрения содержат кобальта 5,4-2,0 мг/кг, никеля 7,0-34,2 мг/кг, свинца - 2,44-48,7 мг/кг, меди - до 14 мг/кг, а калийные удобрения - от 11 до 16 мг/кг никеля и от 1,39 до 17,4 мг/кг свинца [40, 41]. Органические удобрения также являются источником поллютантов. Содержание хрома в навозе может достигать 55 мг/кг, а в компосте - 400 мг/кг, никеля 30 и 279 мг/кг, меди - 172 и 3500 мг/кг, цинка - 556 и 5894 мг/кг, свинца - 27 и 2240 мг/кг [42].
Таким образом, следствием отсутствия канализации и централизованного отопления, широкого несбалансированного применения населением минеральных и органических удобрений является депонирование значительного количества тяжелых металлов в почвах зоны малоэтажной застройки. Продукция, полученная на приусадебных участках, может представлять опасность для потребителей.

\section{Заключение}

Использование различных расчетных параметров загрязнения, несмотря на некоторые различия в оценке степени загрязнения отдельными элементами, позволило выявить детальную картину пространственного распределения тяжелых металлов в почвах урболандшафтов. Почвы урболандшафтов находятся под влиянием сильной техногенной нагрузки. В наиболь- 
шей степени в них накапливаются хром, медь, цинк и свинец, при этом более высокие значения всех показателей загрязнения выявлены в почвах Владивостока Средние и максимальные значения комплексных коэффициентов загрязнения PLI и NPI указывают на деградацию поверхностного слоя городских почв и сильную степень загрязнения тяжелыми металлами. Величина индекса потенциального экологического риска варьирует от незначительной до средней. Степень загрязнения почв различных функциональных зон увеличивается в следующем ряду: рекреационная $<$ многоэтажной застройки < транспортно-селитебная $<$ малоэтажной застройки, при этом уровень загряз-

\section{СПИСОК ЛИТЕРАТУРЫ}

1. Алексеенко В.А., Алексеенко А.В. Химические элементы в геохимических системах. Кларки почв селитебных ландшафтов. - Ростов н/Д.: Изд-во Южного федерального университета, 2013. $-380 \mathrm{c}$.

2. Trace metal contamination in urban soils of China / X.S. Luo, S. Yu, Y.G. Zhu, X.D. Li // Science of the Total Environment. 2012. - V. 421-422. - P. 17-30

3. Brevik E.C., Sauer T.J. The past, present, and future of soils and human health studies // Soil. - 2015. - 1. - P. 35-46.

4. Risk assessment and interpretation of heavy metal contaminated soils on an urban brownfield site in New York metropolitan area / Y. Qian, F. Gallagher, Y. Deng, M. Wu, H. Feng // Environmental Science and Pollution Research. - 2017. - V. 24. - P. 23549-23558

5. Donga R., Jiab Z., Lia S. Risk assessment and sources identification of soil heavy metals in a typical county of Chongqing Municipality, Southwest China // Process Safety and Environmental Protection. - 2018 - V. 3. - P. 275-281.

6. Экологическое состояние городских почв и стоимостная оценка земель / М.Н. Строганова, Т.В. Прокофьева, А.Н. Прохоров, Л.В. Лысак, А.П. Сизов, А.С. Яковлев // Почвоведение. - 2003. - № 7. - С. 867-875.

7. Seleznev A.A., Yarmoshenko I.V., Malinovsky G.P. Urban geochemical changes and pollution with potentially harmful elements in seven Russian cities // Scientific Reports. - 2020. URL https://www.nature.com/articles/s41598-020-58434-4 (дата обращения 10.06.2020).

8. Савченко О.В., Тюпелев П.А. Особенности микроэлементного статуса у детей, проживающих в районах города с разной степенью загрязнения окружающей среды // Экология человека. - 2009. - № 1. - С. 47-50.

9. Наумов Ю.А., Подкопаева О.В. Особенности, тенденции и последствия загрязнения атмосферы городов Приморского края // Территория новых возможностей. Вестник Владивостокского государственного университета экономики и сервиса. 2013. - № 4. - C. $155-171$.

10. Ежегодник. Загрязнение почв России токсикантами промышленного происхождения в 2015 году. - Обнинск: ФГБУ «НПО «Тайфун», 2016. $-112 \mathrm{c}$.

11. Доклад об экологической ситуации в Приморском крае в 2018 году. - Владивосток, 2019. -252 с.

12. Чугаева Н.А., Шишлова Т.М. Сравнительная оценка содержания металлов в составе взвешенных частиц атмосферного воздуха г. Уссурийска // Вестник Северо-восточного научного центра ДВО РАН. - 2015. - № 3. - С. 94-98.

13. Введение почв и почвоподобных образований городских территорий в классификацию почв России / Т.В. Прокофьева, М.И. Герасимова, О.С. Безуглова, К.А., Бахматова А.А. Гольева, С.Н. Горбов, Е.А. Жарикова, Н.Н. Матинян, Е.Н. Наквасина, Н.Е. Сивцева // Почвоведение - 2014 - № 10. - С. 1115-1164

14. Калманова В.Б. Экологический каркас урбанизированных территорий (на примере города Биробиджана) // Известия Самарского научного центра Российской академии наук. 2016. - T. 18. - № 2. - C. 385-388.

15. Содержание тяжелых металлов в почвах селитебных территорий республики Крым / Е.В. Евстафьева, А.М. Богданова, Т.М. Минкина, С.Н. Сушкова, Н.В. Барановская, С.С. Ман- нения колеблется от оценки «чистая» до оценки «сильно загрязненная».

Рациональное использование городских земельных ресурсов предполагает учет сведений о состоянии и свойствах почв различных функциональных зон. Отказ от использования этих данных может привести к неоправданным материальным затратам и снижению комфортности и безопасности среды обитания горожан.

Исследования выполнены при финансовой поддержке Российского фонда фундаментальных исследований (проект № 18-05-00086-A).

джиева, Е.М. Антоненко // Известия Томского политехнического университета. Инжиниринг георесурсов. - 2018. T. 329. - № 10. - C. 19-29.

16. Изменение элементного состава верхнего горизонта почв под воздействием предприятий нефтегазопереработки / В.В. Боев, Н.В., Барановская В.А. Боев, М.Т. Джамбаев, Т.С. Шахова, Л.В. Жорняк // Известия Томского политехнического университета. Инжиниринг георесурсов. - 2019. - Т. 330. - № 11. C. $179-191$.

17. Pollution indices as useful tools for the comprehensive evaluation of the degree of soil contamination. A review / J.B. Kowalska, R. Mazurek, M. Gasiorek, T. Zaleski // Environmental Geochemistry and Health. - 2018. - V. 40. - P. 2395-2420

18. Concentration, spatial distribution, contamination degree and human health risk assessment of heavy metals in urban soils across China between 2003 and 2019 - a systematic review / S. Tong, H. Li, L. Wang, M. Tudi, L. Yang // International Journal Environmental Research and Public Health. - 2020. - V. 17. P. 3099. URL: https://doi.org/10.3390/ijerph17093099 (дата обращения 14.06.2020).

19. Классификация и диагностика почв России / Л.Л. Шишов, В.Д. Тонконогов, И.И. Лебедева, М.И. Герасимова. - Смоленск: Ойкумена, 2004. -342 c.

20. Научно-прикладной справочник по климату СССР. Сер. 3. Многолетние данные. Приморский край. - Л.: Гидрометеоиздат, 1988. - Ч. 1-6. - Вып. 26. - 416 с.

21. ГОСТ 17.4.4.02.2017 Почвы. Методы отбора и подготовки проб для химического, бактериологического, гельминтологического анализа. - М.: Стандартинформ, 2018, - 21 с.

22. М-02-0604-2007 Методика выполнения измерений массовой доли кремния, кальция, титина, ванадия, хрома, бария, марганца, железа, никеля, меди, цинка, мышьяка, стронция, свинца, циркония, молибдена в порошковых пробах почв и донных осадков рентгеноспектральным методом с применением энергодисперсионных рентгенофлуоресцентных спектрометров типа EDX фирмы Shimadzu. - Спб., 2007. - 17 c.

23. Savichev A.T., Vodyanitskii Yu.N. Evaluation of chemical elements contents in soils below the detection limit for X-ray fluorescence analysis and there distribution laws // X-ray fluorescence technology, performance and application. - New York: Nova science publishers, 2018. - P. 89-115.

24. Жарикова Е.А. Почвы Владивостока: основные характеристики и свойства // Вестник ДВО РАН. - 2012. - № 3. - С. 67-73.

25. Жарикова Е.А. Эколого-геохимическое состояние почв рекреационных территорий Уссурийска // Вестник ДВО РАН. 2014. - № 5. - C. 78-85.

26. Жарикова Е.А. Особенности агрохимических свойств и элементного состава почв урбанизированных ландшафтов (на примере г. Уссурийска) // Вестник Алтайского ГАУ. - 2019. № 3. - C.71-76.

27. Kabata-Pendias A. Trace elements in soils and plants. 4th ed. Boca Raton: CRS Press, 2011. -548 p.

28. Muller G. Index of geoaccumulation in sediments of the Rhine River // Geo Journal. - 1969. - V. 2. - P. 108-118.

29. Problems in the assessment of heavy metals in estuaries and the formation pollution index / D.C. Tomlinson, J.G. Wilson, C.R. Harris, D.W. Jeffrey // Helgoland Marine Research. - 1980. V. 33. - P. 566-575. 
30. Hakanson L. An ecological risk index for aquatic pollution control. A sedimentological approach. Water Research. - 1980. - V. 14 (8). P. 975-1001.

31. Characterizing pollution and source identification of heavy metals in soils using geochemical baseline and PMF approach / H.H. Jiang, L.M. Cai, H.H. Wen, J. Luo // Scientific Reports. 2020. - 10:6460. URL: https://doi.org/10.1038/s41598-020-63604-5 (дата обращения 10.06.2020).

32. Varol M. Assessment of heavy metal contamination in sediment of the Tigris River (Turkey) using pollution indices and multivariate statistical techniques // Journal of Hazardous Materials. - 2011. - V. 195. - P. 355-364.

33. Методические указания к выполнению цикла лабораторных работ с элементами научных исследований по курсу «математические методы в геохимических исследованиях» для студентов специальности 08.01.04 (специализация - геология и разведка месторождений радиоактивных и редких элементов). - Томск: Из-во ТПУ, 1994. - 38 с.

34. Environmental quality and sources of heavy metals in the topsoil based on multivariate statistical analyses: a case study in Laiwu City, Shandong Province, China / L. Yu, J. Cheng, J. Zhan, A. Jiang // Natural Hazards. - 2016. - V. 81. - P. 1435-1445.

35. Surface dust heavy metals in the major cities, China / L. Yang, G. Zhu, H. Pan, P. Shi, J. Li, Y. Liu, H. Tong // Environmental Earth Science. - 2017. - V. 76. - P. 757-771.
36. Сайет Ю.Е., Баршакевич И.Л., Ревич Б.А. Методические рекомендации по геохимической оценке источников загрязнения окружающей среды. - М.: ИМГРЭ, 1982. - 111 с.

37. Зверева В.П., Крупская Л.Т. Оценка влияния золоотвалов теплоэлектростанций на объекты окружающей среды (на юге Дальнего Востока) // Экологическая химия. - 2012. - Т. 21. C. $225-233$.

38. Медико-биологическое исследование влияния угольной пыли как фактора интоксикации / Д.В. Фоменко, Е.В. Уланова, К.Г. Громов, А.С. Казицкая, О.И. Бондарев // Бюллетень ВСНЦ СО РАМН. - 2006. - № 1. - С. 278-283.

39. Chen M., Graedel T.E. The potential for mining trace elements from phosphate rock // Journal of Cleaner Production. - 2015. V. 91. - P. 337-346.

40. Trace element composition of selected fertilizers used in Chile: phosphorus fertilizers as a source of long-term soil contamination / M. Molina, F. Aburto, R. Calder, M. Cazanga, M. Escudey // Soil and Sediment Contamination. - 2009. - V. 18. - P. 497-511.

41. Senesi M., Polemio M. Trace element addition to soil by application of NPK fertilizers // Fertilizer Research. - 1981. - V. 2. P. 289-302.

42. Toxic metals in soil-plant systems / Ed. by S.M. Ross. Chichester, England; New York: Wiley, 1994. - 469 p.

Поступила 03.07.2020 г.

\section{Инорормация об авторах}

Жарикова E.A., кандидат биологических наук, старший научный сотрудник Федерального научного центра Биоразнообразия наземной биоты Восточной Азии Дальневосточного отделения РАН 


\title{
UDC $631.445+504.05$
}

\section{ASSESSMENT OF HEAVY METALS CONTENT AND ENVIRONMENTAL RISK IN URBAN SOILS}

\author{
Elena A. Zharikova, \\ ejarikova@mail.ru
}

Federal Scientific Center of the East Asia Terrestrial Biodiversity, Far East Branch of the Russian Academy of Sciences, 159, 100-letiya Vladivostoka avenue, Vladivostok, 690022, Russia.

\begin{abstract}
The relevance of the study is caused by the need to reveal the features of accumulation of heavy metals in the soils of the urban landscapes of Vladivostok and Ussuriysk and to establish the value of the potential environmental risk.

The main aim of the work is to assess the geochemical state of soils in various functional zones of urban landscapes using several pollution indices.

Methods. The total content of trace elements in soils was determined by x-ray fluorescence spectroscopy using an EDX-800HS (Shimadzu) spectrometer.

Results. Chromium, copper, zinc and lead are accumulated to the greatest extent in the upper soil horizons of urban landscapes under the influence of a strong technogenic load. The content of vanadium, cobalt, and nickel is comparable to or lower than clark. The average and maximum values of complex pollution coefficients PLI and NPI indicate the degradation of the surface layer of urban soils and a strong degree of heavy metal pollution. The value of the potential environmental risk index varies from small to medium. The soil pollution level in various functional zones increases in the following series: recreational zone<zone of multi-storey buildings<transport and residential zone<zone of low-rise buildings, while the level of pollution varies from the assessment of «clean» to the assessment of «highly polluted». Weak accumulation of chromium, zinc and copper was detected in some soils of recreational zones. A noticeable increase in the content of various heavy metals was found in the soils of Vladivostok multi-storey development zone, increase in the copper content was noted in Ussuriysk. Chromium, copper, lead and zinc are accumulated in the soils of transport and residential zone and low-rise buildings zone with varying degrees of intensity. Higher values of both individual (Igeo, EF, PI) and complex pollution indicators (NPI, PLI, PERI) were found in the soils of Vladivostok.
\end{abstract}

\section{Key words:}

Urban landscape soils, pollutants, heavy metals, environmental risk, pollution index.

The research was financially supported by the Russian Foundation for Basic Research (project no. 18-05-00086-A).

\section{REFERENCES}

1. Alekseenko V.A., Alekseenko A.V. Khimicheskie elementy $y$ geokhimicheskikh sistemakh. Klarki pochv selitebnykh landshaftov [Chemical elements in geochemical systems. Clarcs of soils of residential landscapes: monograph]. Rostov n/D, Southern Federal University Press, 2013.380 p.

2. Luo X.S., Yu S., Zhu Y.G., Li X.D. Trace metal contamination in urban soils of China. Science of the Total Environment, 2012, vol. 421-422, pp. 17-30.

3. Brevik E.C., Sauer T.J. The past, present, and future of soils and human health studies. Soil, 2015, no. 1, pp. 35-46.

4. Qian Y., Gallagher F., Deng Y., Wu M., Feng H. Risk assessment and interpretation of heavy metal contaminated soils on an urban brownfield site in New York metropolitan area. Environmental Science and Pollution Research, 2017, vol. 24, pp. 23549-23558.

5. Donga R., Jiab Z., Lia S. Risk assessment and sources identification of soil heavy metals in a typical county of Chongqing Municipality, Southwest China. Process Safety and Environmental Protection, 2018, vol. 3, pp. 275-281.

6. Stroganova M.N., Prokofeva T.V., Lysak L.V., Prokhorov A.N., Yakovlev A.S., Sizov A.P. Ecological status of urban soils and economic evaluation of lands. Eurasian Soil Science, 2003, vol. 36 no. 7, pp. 780-787.

7. Seleznev A.A., Yarmoshenko I.V., Malinovsky G.P. Urban geochemical changes and pollution with potentially harmful elements in seven Russian cities. Scientific Reports, 2020. Available at: https://www.nature.com/articles/s41598-020-58434-4 (accessed 10 June 2020).

8. Savchenko O.V., Toupeleev P.A. Features of the microelement status in children lived in city areas with the different degrees of environmental contamination. Human Ecology, 2009, no. 1, pp. 47-50. In Rus.

9. Naumov Y.A., Podkopaeva O.V. Features, trends and effects of air pollution to the cities of Primorsky Region. The territory of new opportunities. The herald of Vladivostok state university of economics and service, 2013, no. 4, pp.155-171.
10. Ezhegodnik. Zagryaznenie pochv Rossii toksikantami promyshlennogo proiskhozhdeniya $v 2015$ godu [Yearbook. Contamination of Russian soils with toxicants of industrial origin in 2015]. Obninsk, FGBU «NPO «Tajfun», 2016. 112 p.

11. Doklad ob ekologicheskoy situatsii v Primorskom krae v 2018 godu [Report about the environmental situation in the Primorsky territory in 2018]. Vladivostok, 2019. $252 \mathrm{p}$.

12. Chugaeva N.A., Shishlova T.M. Comparative evaluation of metal content in the atmospheric air of the city of Ussuriysk. Bulletin of the North-East Scientific Center, Russia Academy of Sciences Far East Branch, 2015, no. 3, pp. 94-98. In Rus.

13. Prokofeva, T.V., Gerasimova, M.I., Bezuglova, O.S., Bakhmatova K.A., Goleva A.A., Gorbov S.N. , Zharikova E.A., Matinyan N.N., Nakvasina E.N., Sivtseva N.E. Inclusion of soils and soil-like bodies of urban territories into the Russian soil classification system. Eurasian Soil Science, 2014, vol. 47, no. 10, pp. $959-967$.

14. Kalmanova V.B. The ecological framework of the urbanized territories (on the example of Birobidzhan city). Izvestia of Samara Scientific Center of the Russian Academy of Sciences, 2016, vol. 18, no. 2, pp. 385-388. In Rus.

15. Evstafeva E.V., Bogdanova A.M., Minkina T. M., Sushkova S.N., Baranovskaya N.V., Mandzhieva S.S., Antonenko E.M. Heavy metals content in soils of residential territories of Krimea republic. Bulletin of the Tomsk Polytechnic University. Geo Assets Engineering, 2018, vol. 329, no. 10, pp. 19-29. In Rus.

16. Boev V.V., Baranovskaya N.V., Boev V.A., Yambayev M.T., Shakhova T.S., Zhornyak L.V. Change of elemental composition of soil upper horizon under the influence of oil and gas refining enterprises. Bulletin of the Tomsk Polytechnic University. Geo Assets Engineering, 2019, vol. 330, no. 11, pp. 179-191. In Rus.

17. Kowalska J.B., Mazurek R., Gasiorek M., Zaleski T. Pollution indices as useful tools for the comprehensive evaluation of the degree of soil contamination. A review. Environmental Geochemistry and Health, 2018, vol. 40, pp. 2395-2420. 
18. Tong S., Li H., Wang L., Tudi M., Yang L. Concentration, spatial distribution, contamination degree and human health risk assessment of heavy metals in urban soils across China between 2003 and 2019 - a systematic review. International Journal Environmental Research and Public Health, 2020, vol. 17, pp. 3099. Available at: https://doi.org/10.3390/ijerph17093099 (accessed 14 June 2020).

19. Shishov L.L., Tonkonogov V.D., Lebedeva I.I., Gerasimova M.I. Klassifikatsiya i diagnostika pochv Rossii [Classification and soil diagnostics of Russia]. Ed. by G.V. Dobrovolskiy. Smolensk, Oykumena Publ., 2004. 342 p.

20. Nauchno-prikladnoy spravochnik po klimatu SSSR. Ser. 3 Mnogoletnie dannye. Primorskiy kray [Referent book on Climate in the Soviet Union. Ser. 3: Long-Term Data. Primorskii Region] Leningrad, Gidrometeoizdat Publ., 1988. Ch. 1-6, Iss. 26, 416 p.

21. GOST 17.4.4.02.2017 Pochvy. Metody otbora i podgotovki prob dlya khimicheskogo, bakteriologicheskogo, gelmintologicheskogo analiza [SS 17.4.4.02.2017 Soils. Methods of sample selection and preparation for chemical bacterial and helminthological analysis]. Moscow, Standardinform Publ., 2018. 21 p.

22. M-02-0604-2007 Metodika vypolneniya izmereniy massovoy doli kremniya, kaltsiya, titina, vanadiya, khroma, bariya, margantsa zheleza, nikelya, medi, tsinka, myshyaka, strontsiya, svintsa, tsirkoniya, molibdena $v$ poroshkovykh probakh pochv $i$ donnykh osadkov rentgenospektralnym metodom $s$ primeneniem energodispersionnykh rentgenofluorescentnykh spektrometrov tipa EDX firmy Shimadzu [Methods for measuring the mass fraction of silicon, calcium, titine, vanadium, chromium, barium, manganese, iron, nickel, copper, zinc, arsenic, strontium, lead, zirconium, and molybdenum in powder samples of soils and bottom]. StPetersburg, 2007. $17 \mathrm{p}$.

23. Savichev A.T., Vodyanitskii Yu.N. Evaluation of chemical elements contents in soils below the detection limit for X-ray fluorescence analysis and there distribution laws. X-ray fluorescence technology, performance and application. New York, Nova science publishers, 2018. pp. 89-115.

24. Zharikova E.A. Soils of Vladivostok: main characteristics and properties. Vestnik of the Far East Branch of the Russian Academy of Sciences, 2012, no. 3, pp. 67-73. In Rus.

25. Zharikova E.A. Ecology-geochemical condition of soils of recreational areas of Ussuriysk. Vestnik of the Far East Branch of the Russian Academy of Sciences, 2014, no. 5. pp. 78-85. In Rus.

26. Zharikova E.A. Soils agrochemical properties and elemental composition features in urban landscapes (case study of the city of Ussuriysk). Vestnik Altayskogo gosudarstvennogo agrarnogo universiteta, 2019, no. 3, pp. 71-76. In Rus.

27. Kabata-Pendias A. Trace Elements in Soils and Plants. $4^{\text {th }}$ ed. Boca Raton, CRS Press, 2011. 548 p.

28. Muller G. Index of geoaccumulation in sediments of the Rhine River. Geo Journal, 1969, vol. 2, pp. 108-118.

29. Tomlinson D.C., Wilson J.G., Harris C.R., Jeffrey D.W. Problems in the assessment of heavy metals in estuaries and the formation pollution index. Helgoland Marine Research, 1980, vol. 33, pp. 566-575.

30. Hakanson L. An ecological risk index for aquatic pollution control A sedimentological approach. Water Research, 1980, vol. 14 (8), pp. $975-1001$.

\section{Information about the authors}

Elena A. Zharikova, Cand Sc., senior researcher, Federal Scientific Center of the East Asia Terrestrial Biodiversity, Far East Branch of the Russian Academy of Sciences.
31. Jiang H.H., Cai L.M., Wen H.H., Luo J. Characterizing pollution and source identification of heavy metals in soils using geochemical baseline and PMF approach. Scientific Reports, 2020, 10:6460. Available at: https://doi.org/10.1038/s41598-020-63604-5 (accessed 10 June 2020).

32. Varol M. Assessment of heavy metal contamination in sediments of the Tigris River (Turkey) using pollution indices and multivariate statistical techniques. Journal of Hazardous Materials, 2011, vol. 195, pp. 355-364.

33. Metodicheskie ukazaniya $k$ vypolneniyu tsikla laboratornykh rabot s elementami nauchnykh issledovaniy po kursu «Matematicheskie metody $v$ geokhimicheskikh issledovaniyakh» dlya studentov spetsialnosti 08.01 .04 (specializatsiya - geologiva i razvedka mestorozhdeniy radioaktivnykh $i$ redkikh elementov) [Guidelines for performing a cycle of laboratory work with elements of scientific research in the course «Mathematical methods in geochemical research» for students of specialty 08.01.04 (specialization-Geology and exploration of deposits of radioactive and rare elements)]. Tomsk, TPU Publ. house, 1994. 38 p.

34. Yu L. Cheng J., Zhan J., Jiang A. Environmental quality and sources of heavy metals in the topsoil based on multivariate statistical analyses: a case study in Laiwu City, Shandong Province, China. Natural Hazards, 2016, vol. 81, pp. 1435-1445.

35. Yang L., Zhu G., Pan H., Shi P., Li J., Liu Y., Tong H. Surface dust heavy metals in the major cities, China. Environmental Earth

36. Sayet Yu.E., Barshakevich I.L., Revich B.A. Metodicheskie rekomendatsii po geokhimicheskoy otsenke istochnikov for geochemical assessment of pollution sources of the environment]. Moscow, IMGRE Publ., 1982. $111 \mathrm{p}$.

37. Zvereva V. P., Krupskaya L. T. Estimation of Influence of Ash Dumps of Thermoelectric Plants on Environment Features (in South Far East). Ekologicheskaya ximiya, 2012, vol. 21, pp. 225-233. In Rus.

38. Fomenko D.V., Ulanova E.V., Gromov K.G., Kaztskaya A.S., Bondarev O.I. Mediko-biologicheskoe issledovanie vliyaniya ugolnoy pyli kak faktora intoksikatsii [Medical and biological research of coal dust affect as intoxication factor]. Bulletin Vostochno-Sibirskogo Nauchnogo Centra Sibirskogo Otdeleniya Akademii Medicinskix Nauk, 2006, no. 1, pp. 278-283.

39. Chen M., Graedel T.E. The potential for mining trace elements from phosphate rock. Journal of Cleaner Production, 2015, vol. 91, pp. 337-346.

40. Molina M., Aburto F., Calder R., Cazanga M., Escudey M. Trace element composition of selected fertilizers used in Chile: phosphorus fertilizers as a source of long-term soil contamination. Soil and Sediment Contamination, 2009, vol. 18, pp. 497-511.

41. Senesi M., Polemio M. Trace element addition to soil by application of NPK fertilizers. Fertilizer Research, 1981, vol. 2, pp. 289-302.

42. Toxic metals in soil-plant systems. Ed. by S.M. Ross. Chichester, England, New York, Wiley. 1994. 469 p.

Received: 3 July 2020. Science, 2017, vol. 76, pp. 757-771. zagryazneniya okruzhayushhey sredy [Methodic recommendations 